\title{
MECHANICAL BEHAVIOR OF STEEL PIPES WITH LOCAL WALL DISTORTIONS UNDER CYCLIC LOADING
}

\author{
Aglaia E. Pournara \\ Department of Mechanical Engineering \\ University of Thessaly \\ Volos, Greece \\ email: agpourna@gmail.com
}

\author{
Spyros A. Karamanos \\ Department of Mechanical Engineering \\ University of Thessaly \\ Volos, Greece \\ email: skara@mie.uth.gr
}

\begin{abstract}
Evaluating the severity of pipe wall distortions is a crucial step towards safeguarding the structural integrity of aging hydrocarbon pipeline infrastructure. The present research refers to the remaining life of oil and gas transmission steel pipelines with local wall distortions (i.e. dents and buckles) under repeated loading. The research described in this paper constitutes the first part of a large numerical/experimental research project, aimed at developing methodologies and relevant design guidelines towards assessing and repairing structural pipeline damages in the form of local wall distortions. The paper describes numerical research aimed at investigating the residual structural integrity of smooth dented and buckled steel pipes, with respect to repeated loading that causes fatigue, with the purpose of designing large-scale experiments. Finite element models are developed to simulate the formation of dents and buckles on the pipe wall at various sizes (depths). The deformed steel pipes are further subjected to cyclic pressure or cyclic bending loading in order to estimate the remaining fatigue life of the deformed pipe. The local stress and strain variations due to cyclic loading application are calculated numerically at the deformed area of the pipe wall. In addition, the local strain variations are expressed in terms of strain concentration factors (SNCF) at the critical region of the pipe.
\end{abstract}

\section{INTRODUCTION}

Pipelines may exhibit structural failure because of damage due to external interference, mechanical damage, or corrosion [1][2][3]. In particular, the presence of dents caused by and local buckles (in the form of sharp dents) on the pipeline wall, caused by excessive imposed bending, are associated with significant stress and strain concentrations at the dented area and constitute a possible threat for the structural integrity of pipelines [3].The present paper describes on-going research based on numerical simulations, conducted to examine the influence of local buckles on the fatigue strength of steel pipelines.

Using four different two-dimensional shape functions to describe dent geometry, Ong [4] calculated local stresses at the pipe wall of a pressurized elastic pipe with a long smooth dent and found that the maximum local elastic stress varies between 14 and 21 times the value of the nominal hoop stress due to pressure. Ong et al. [5], using finite element simulation, calculated local elastic stresses at short and smooth dents, in pressurized dented cylinders. The peak elastic stress in short dents was found to be significantly less than in long dents. It was also concluded that the presence of local dents does not affect the burst capacity of the dented pipeline.

An experimental and numerical investigation of the fatigue resistance of offshore pipelines with plain (smooth) dents under cyclic pressure has been reported in [6]. A longitudinal wedge shaped denting tool was employed to dent 12 in. steel pipe specimens at depths ranging between $5 \%$ and $20 \%$ of their diameter. It was found that plain (smooth) dents with a depth larger than 5\% may result in a reduction of the pipeline fatigue strength. Buitrago and Hsu [7], using a finite element simulation, investigated the fatigue response of tubular members containing relatively smooth dents and provided stress concentration factors in the form of parametric equations in terms of geometric parameters for axial and bending loads.

Recently, the effect of various defects (gouges, manufacturing or weld defects, corrosion) on the structural integrity of pipelines has been examined in a joint industry project [3][8], based on existing experimental and numerical results. Considering a large number of publications regarding the ultimate capacity or the fatigue strength of defected or damaged pipelines, listed in [3][8], the present study aims at the 
enhancement of the current methodologies towards a "fitnessfor-purpose" pipeline assessment. It was found that very limited data exist for the influence of buckles on the fatigue resistance of pipelines, while the fatigue capacity due to bending loads is not yet included.

Das et al. [9] conducted full-scale laboratory tests to investigate the post-wrinkling ultimate behavior of steel pipelines. The pipe specimens exhibited extreme ductile behavior and did not fail in fracture under monotonically increasing axisymmetric compressive axial loads and displacements. Fractures developed at the wrinkled region, however, when a wrinkled pipe specimen was subjected to cyclic strain reversals due to unloading and loading of primary loads. More recently, Dama et al. [10] presented experimental and numerical research conducted to assess the structural condition of buckled pipes, subjected to both bending and internal pressure. Fatigue failure under repeated loading and pipe burst have investigated, through three full-scale buckled pipe specimens and nonlinear finite element tools as shown in Figure 1. The maximum strain range from the finite element computations, and a simple S-N approach gave reasonable predictions for the number of cycles to failure observed in the tests. The results of the present study demonstrate that under repeated loading, fatigue failure occurs in the buckled area at the location of maximum strain range.
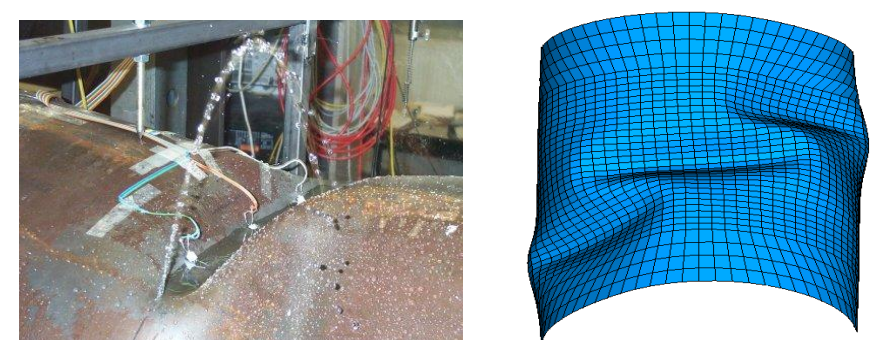

Figure 1: Fatigue cracking of buckled pipe under cyclic loading; test and numerical simulation [10]

The present study refers to structural integrity of steel pipelines with smooth dents due to external interference and with local buckles due to excessive pipeline bending. In particular, the paper investigates the reduction of structural capacity in dented and buckled steel pipelines, subjected to cyclic bending loads and internal pressure, toward estimating their remaining operating life and strength. In the presence of such wall distortions, the pipeline can still fulfill its transportation function, provided that the steel material is adequately ductile and no cracks occur. However, the damaged area is associated with significant strain concentrations and, in the case of repeated loading cracks may develop, leading to fatigue failure. In the numerical results, strain concentration factors (SNCF) are estimated for buckled and dent pipes under cyclic bending and pressure loading.

\section{PIPE SPECIMENS AND SET-UP DESCRIPTION}

The present paper is the first part of a large research investigation, aimed at examining the remaining strength and fatigue life of dented and buckled pipes. Experimental research is planned for this investigation, supported by extensive numerical simulations. In the present paper, preliminary numerical results are presented, which aim at designing the experimental testing program.

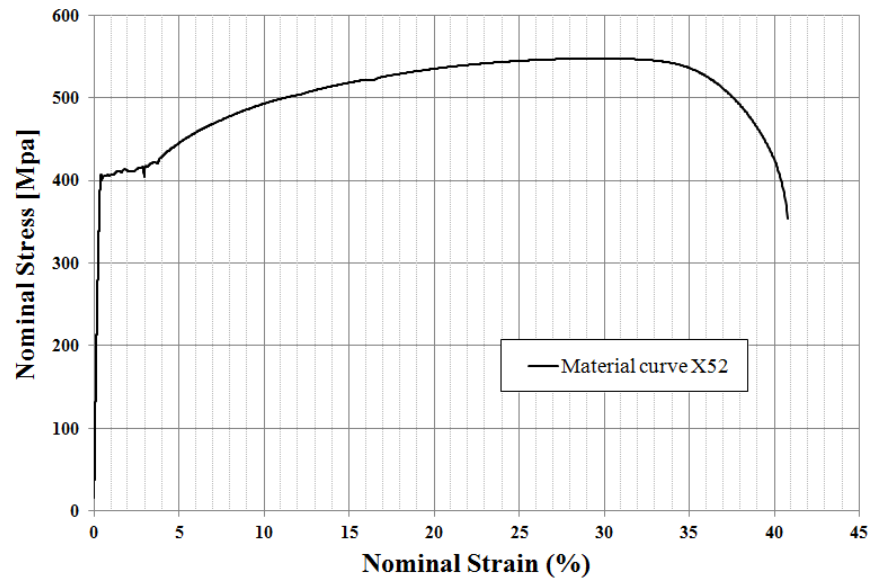

(a)

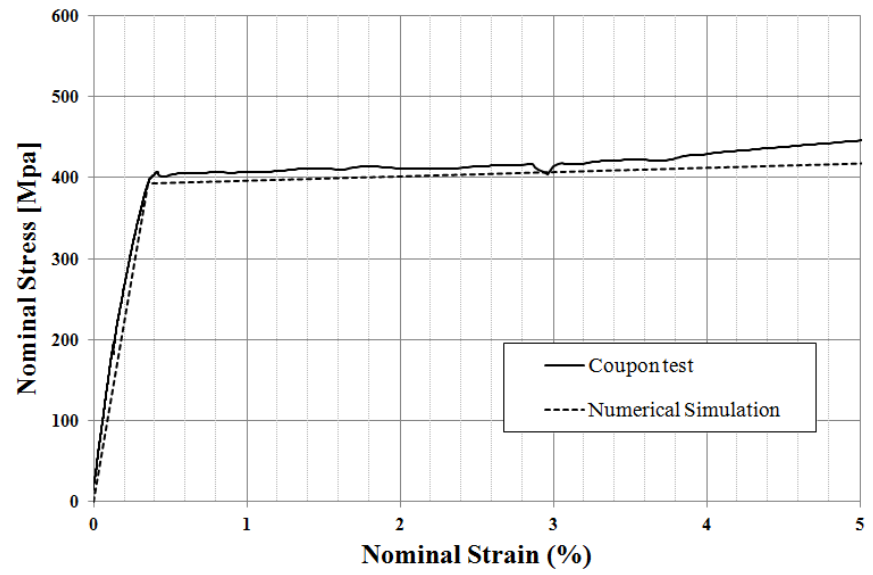

(b)

Figure 2: Stress-strain curve for API 5L X52 steel material (as measured); (a) complete curve and (b) detail of curve and numerical modeling.

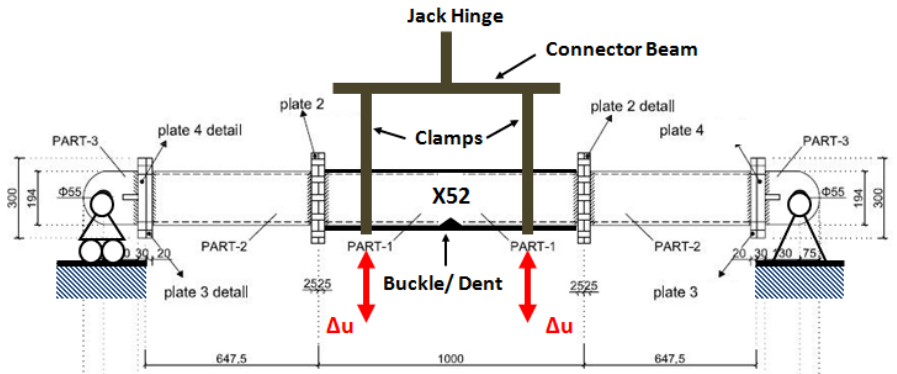

Figure 3: Schematic layout for cyclic testing of buckled/dented pipes.

The specimens to be tested are 6-inch line pipes with nominal diameter and thickness equal to 6.625 in $(168.3 \mathrm{~mm})$ and $4.78 \mathrm{~mm}$ respectively. The length of the 6-inch test specimens is $950 \mathrm{~mm}$. The steel material is API $5 \mathrm{~L}$ grade $\mathrm{X} 52$, and the stress-strain curve from a uniaxial test is shown in Figure 2a. The actual yield stress is considered equal to $\sigma_{\mathrm{y}}=406$ 
$\mathrm{MPa}$, while the material presents a ductile behavior with elongation at maximum nominal stress equal to $29 \%$.

The specimens are first either dented, with the use of a wedge, or buckled, with the application of excessive bending. Subsequently, the pipes are subjected to cyclic bending, under a displacement-controlled scheme, until fatigue cracking occurs at the damaged area.

For the case of cyclic bending loading, each of the 6-inch pipes is connected to two stiff tubular parts, as shown in Figure 3. Those tubular members are 7-inch-diameter with nominal outer diameter and thickness equal to $193.7 \mathrm{~mm}$ and $10 \mathrm{~mm}$ respectively. Their length is $832.5 \mathrm{~mm}$, so that the total length of the specimen is $2615 \mathrm{~mm}$, their material is high strength steel, with measured yield stress equal to $735 \mathrm{MPa}$, and they are rigidly connected (bolted) to the 6-inch test specimen through the use of end plates. The two ends of the entire specimen are hinged and a four-point bending loading scheme is applied to the specimen, through the use of a cross beam, also shown in Figure 3. Bending load is introduced through wooden clamps so that localized strains developed at the contact area between the clamp and the outer pipe wall will not deform the pipe locally. The wooden clamps are connected to the hydraulic cylinder through a non-deformable horizontal steel cross-beam.

For the case of cyclic pressure loading, the 6-inch pipes are capped and internally pressurized in a cyclic pattern. The ratio of minimum-to-maximum pressure is equal to 0.1 , with the maximum pressure equal to the maximum operating pressure:

$$
p_{\max }=0.72 \times\left(2 \sigma_{y} t / D\right)
$$

Under those cyclic pressure loading conditions, fatigue cracking occurs at the damaged area.

\section{FINITE ELEMENT SIMULATION}

Nonlinear finite element tools have been employed to simulate the development of the denting/buckling and the behavior of those damaged pipes under cyclic bending and pressure loading.

The simulations are conducted with finite element program ABAQUS, and the finite element models are capable of describing large displacements and strains, as well as inelastic effects rigorously. Similar to the work reported in [10], the pipe is simulated with four-node reduced-integration shell elements (S4R), which have shown to perform very well in nonlinear analysis problems involving large inelastic deformations of relatively thick-walled steel cylinders. In order to accomplish a good approximation of the dent profile and local stress distribution, the element mesh is rather dense at a two-diameterlong region, about the middle section of the pipe, where the dent is located.

To simulate the application of lateral loading, as shown in Figure 3, the corresponding cross-sectional nodes are coupled kinematically with a fictitious node, referred to as "reference node", located at the center of the cross-section. The highstrength steel "stiff" tubular members connecting the test pipes to the hinges are modeled as beam elements.

To describe inelastic material behavior, a $J_{2}$ (von Mises) plasticity model with linear kinematic hardening is employed. The plasticity model is calibrated through appropriate uniaxial tensile tests on steel coupon specimens, extracted from the X52 6-inch pipes, shown in Figure 3; the yield stress is taken equal to $393 \mathrm{MPa}$ (the mean value of three coupon tests) with a constant hardening modulus equal to $530 \mathrm{MPa}(\mathrm{E} / 210)$.

\section{SIMULATION OF PIPE DENTING}

The finite element model for simulating the denting procedure consists of five parts; the denting tool, the tubular member, the base plate which prevents pipe movement during indentation, and the two stiff pipe segments, which connect the pipe specimen with the hinges of the experimental set up, and are rigidly connected (bolted) to the two ends of the 6-inch pipe specimens.

The wedge-type denting tool is oriented in a direction perpendicular to the pipe axis, and its shape is shown Figure 4a. The total height is equal to $125 \mathrm{~mm}$ and the horizontal dimension is $200 \mathrm{~mm}$. The radius of the rounded wedge is equal to $5 \mathrm{~mm}$. The denting tool is designed as analytical rigid part unable to deform. Contact interaction is applied between the intender surface and the outer pipe wall surface.

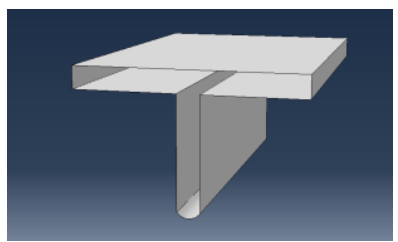

(a)

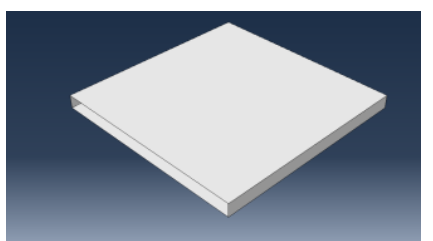

(b)
Figure 4: Rigid models for denting tool and support plate

The bottom square plate with dimensions $300 \mathrm{~mm} \times 300 \mathrm{~mm}$ is shown in Figure $4 \mathrm{~b}$, and is necessary to support the pipe during the indentation process, and prevents its downward movement. The plate is also considered as a rigid (nondeformable) part, and contact conditions are assumed between its surface and the pipe outer surface, which do not allow penetration of one surface into the other, but permit pipe uplifting.

The total configuration of the model is shown in Figure 5a. The pipe model is resting on the rigid plate. The denting tool moves downwards through a displacement control scheme up to a prescribed displacement, and returns to its initial position. During the denting process, the two pipe ends are free, resulting in a small uplifting. Two values for the applied denting displacement are considered in this study, namely $9 \%$ and $15 \%$ of the pipe diameter. After the removal of the denting tool and the elastic rebound, the corresponding values of the residual dents $d_{d}$ are $3.5 \%$ and $6 \%$ of the pipe diameter $D$. These values are close to the acceptable values of smooth (nongauged) dents stated by the new relevant provisions of ASME B31.8, briefly described in the Appendix.

The dent profile and the stress distribution around the dent region after the elastic rebounding are shown in Figure 5b. Moreover, force versus denting displacement curves are identified for both dent cases during the denting procedure and after the indenter removal as shown in Figure 6. 

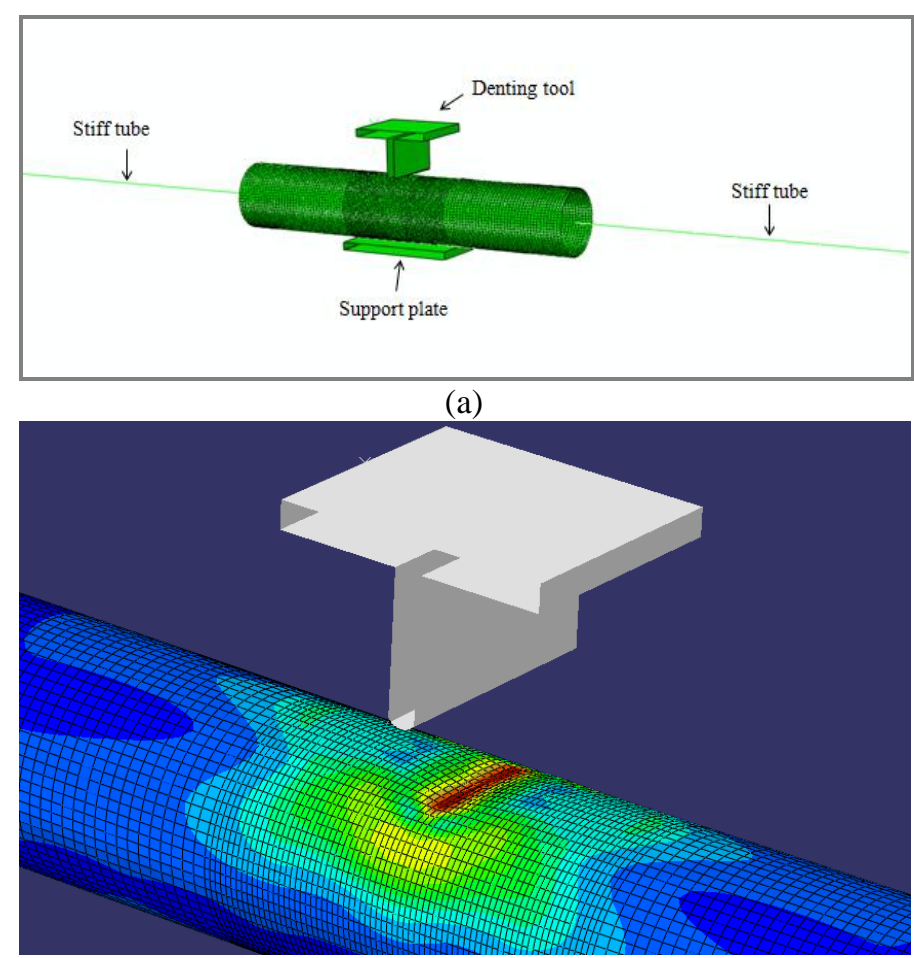

(b)

Figure 5: Finite element model after denting procedure.

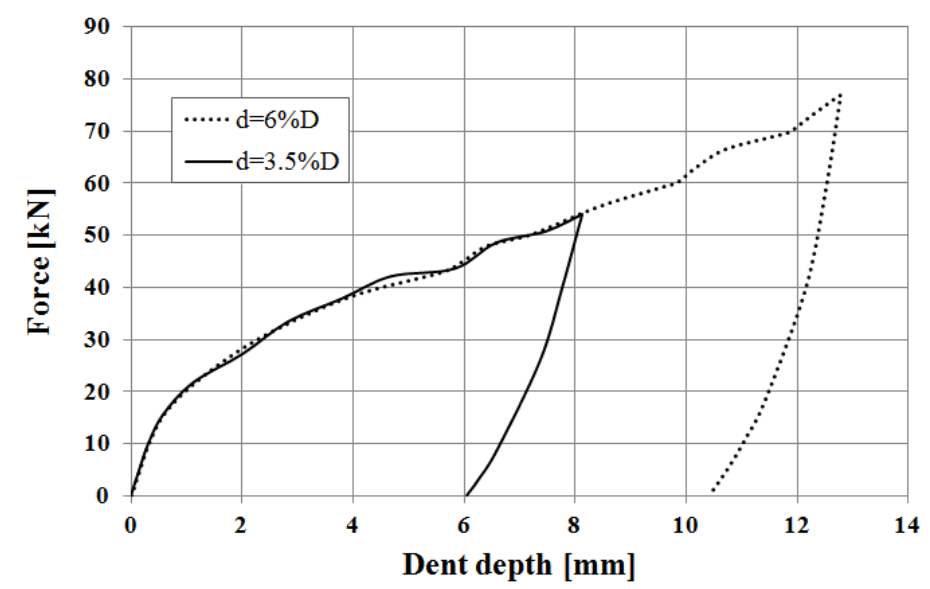

Figure 6: Force versus denting displacement during denting procedure.

\section{SIMULATION OF PIPE BUCKLING}

To simulate the formation of local buckling, the pipes, together with the stiff tubular segments, are subjected to monotonic bending loading, under four-point bending conditions. In the present model, the load is applied considering two fictitious nodes (reference nodes) that couple kinematically all the shell nodes of the circumference where the wooden grips are located. The general configuration of the simply-supported model under bending conditions follows closely the experimental set-up shown in Figure 3 and the buckled shape of the pipe is shown in Figure 7. The load-displacement curve for the four-point bending procedure with unloading is shown in Figure 8.

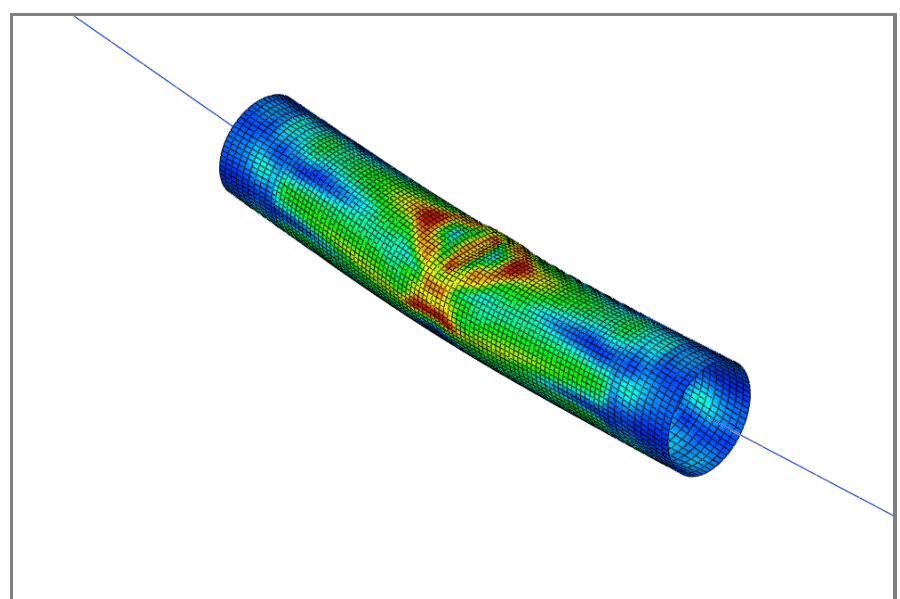

Figure 7: Buckled shape of bent pipe.

An important note is necessary at this point. Because of four-point bending, the central part of the specimen exhibits a uniform distribution of bending moment, so that the buckle may occur at any location along this central part, possibly at the points of load application. To enforce the formation of buckle at the middle of the specimen, a transverse (radial) load is introduced at the compression side of the central section. This transverse load is applied upon the bent pipe reaches some plastic deformation (point A) and introduces an initial wrinkling imperfection that enables the formation of local buckling (point B) at the desired location as shown in Figure 8.

Three values of buckle size (depth) $d_{b}$ are considered, with values of $5.62 \%, 6.21 \%$ and $11.46 \%$ of the pipe diameter, measured after pipe unloading and elastic rebound. The geometry of these buckles fall within the acceptability limits for smooth (non-gauged) dents stated in ASME B31.8 (see Appendix).

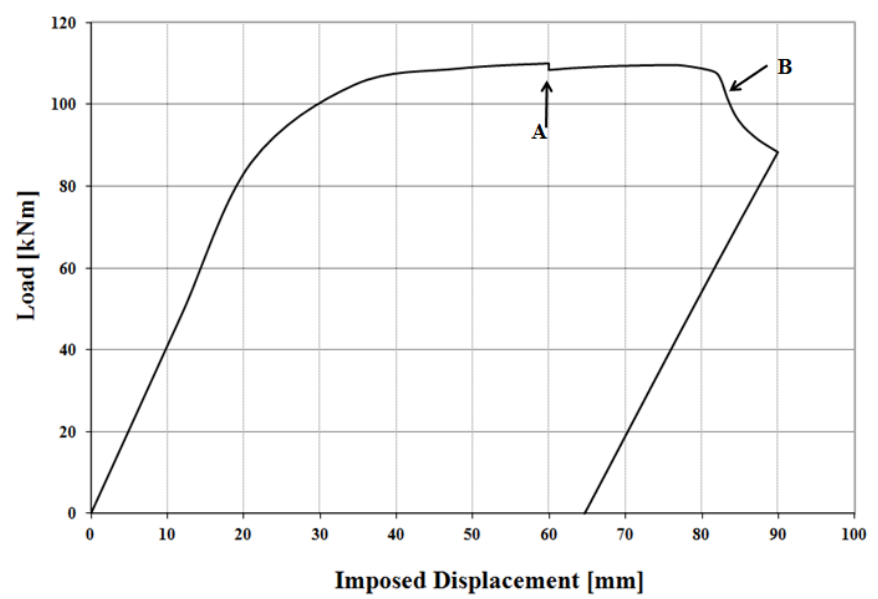

Figure 8: Load displacement curve for bending of pipes; local buckling formation.

\section{CYCLIC LOADING OF DAMAGED PIPES}

Cyclic loading of initially damaged (dented and buckled) pipes is simulated, under bending and pressure. Two or three levels of initial damage are considered for each case, as described in the previous section. Some representative results 
are presented below. The main purpose the numerical analyses is to obtain a preliminary estimate of the so-called "strain concentration factor" (SNCF) at the critical buckle region under cyclic loading, defined by the following ratio:

$$
S N C F=\frac{\Delta \varepsilon_{\max }}{\Delta \varepsilon_{\text {nom }}}
$$

where $\Delta \varepsilon_{\max }$ is the maximum local strain range at the buckled/dented (critical) region and $\Delta \varepsilon_{n o m}$ is the nominal strain range due to the applied loading, calculated through elementary mechanics of mechanics, considering the initial (intact) geometry of the member.

\section{Cyclic bending loading}

In this loading case, the strain concentration factor is computed through the measurement of the maximum strain variation in the longitudinal direction of the pipe. For the present case, $\Delta \varepsilon_{\text {nom }}$ is calculated as follows:

$$
\Delta \varepsilon_{\text {nom }}=\frac{12 D}{L^{2}\left[3-(\alpha / L)^{2}\right]} \Delta u
$$

where $L$ is the total length of the test configuration (herein equal to $2615 \mathrm{~mm}$ ) including both end sections, $\alpha$ is the distance between the hinge support and the point of load application, $\Delta u$ is the range of the imposed displacement which is constant for every cycle.

Dented pipes are examined first for both sizes of denting $(6 \% \mathrm{D}$ and $10 \% \mathrm{D})$. After the development of the dent and the elastic rebounding, 6 cycles of cyclic bending were subjected on the dented specimen through displacement control of $\Delta u=50 \mathrm{~mm}$. The cyclic response of the dented models is shown in Figure 9.

It is shown that hysteresis loops are developed associated with significant plastic deformation for both cases of dents. This indicates that although these dents satisfy the acceptability limits for operation according to current provisions (ASME B31.8), the accumulation of plastic deformation may result in low-cycle fatigue and failure. Moreover, as reported in Table 1, the factor SNCF which is computed for both dent cases at the critical dent region after six (6) bending loading cycles, is consistent with those in Dama et al [10].

\begin{tabular}{|c|c|c|c|c|c|c|c|}
\hline \multirow[t]{2}{*}{$\begin{array}{l}\text { DENTED } \\
\text { PIPE }\end{array}$} & \multirow{2}{*}{$\begin{array}{l}\text { Depth }\left(d_{d}\right) \\
\text { [mm] }\end{array}$} & \multirow[t]{2}{*}{$\begin{array}{l}\mathrm{d} / \mathrm{D} \\
(\%)\end{array}$} & \multicolumn{2}{|c|}{$\begin{array}{c}\text { Geometric Strain } \\
\text { Calculations } \\
\text { (ASME B31.8) }\end{array}$} & \multirow[t]{2}{*}{$\begin{array}{l}\text { Cyclic } \\
\text { Bending } \\
\Delta \mathbf{u}[\mathrm{mm}]\end{array}$} & \multirow{2}{*}{$\begin{array}{c}\text { Cyclic } \\
\text { Pressure } \\
\Delta \mathrm{P} \\
{[\mathrm{MPa}]}\end{array}$} & \multirow[t]{2}{*}{ SNCF } \\
\hline & & & $\varepsilon_{i}(\%)$ & $\varepsilon_{0}(\%)$ & & & \\
\hline 1 & 6.1 & 3.5 & 6.1 & 6.4 & 50 & -- & 9.2 \\
\hline 2 & 10.1 & 6 & 7.5 & 7.9 & 50 & -- & 10.46 \\
\hline
\end{tabular}

Table 1. Finite element results for dented pipes

It is also observed that for both sizes of dent depth, the region of maximum concentration of plastic deformation is located at the right and left ridges of the dent profile, along the transverse direction of the longitudinal axis of the tubular model.

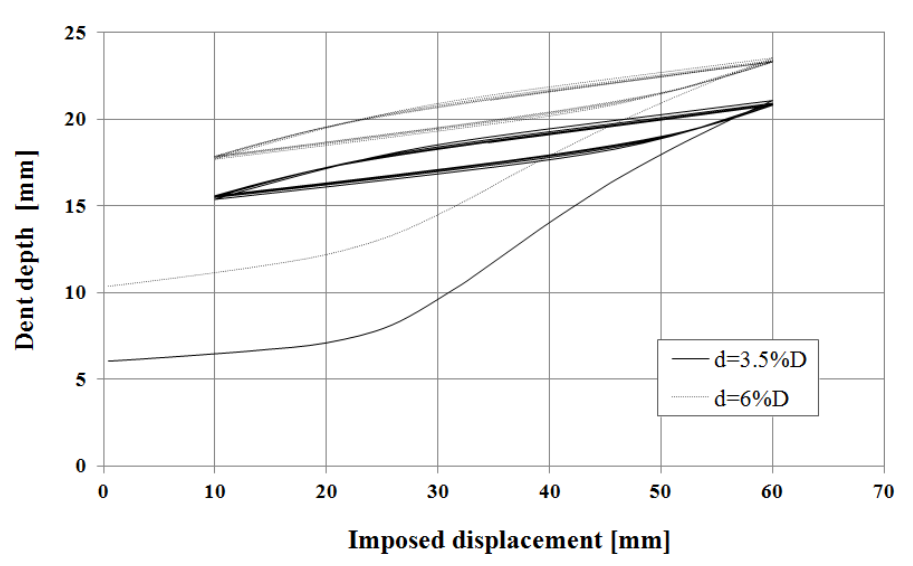

(a)

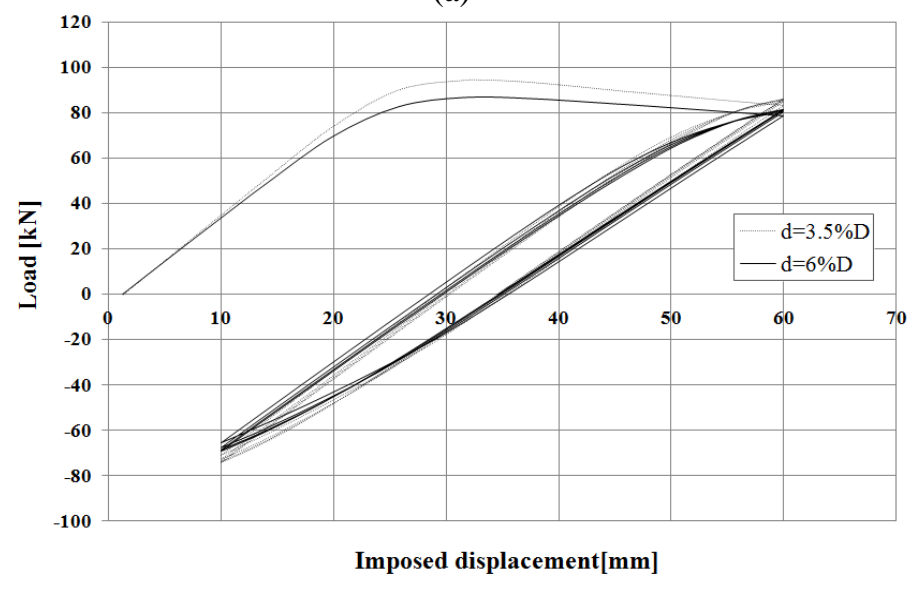

(b)

Figure 9: Cyclic loading behavior for dented pipes.

Similar to the dented pipes, six (6) cycles of constant vertical displacement variation $(\Delta u)$ equal to $60 \mathrm{~mm}$ are applied on each buckled pipe after the development and the elastic rebound of the buckle as shown in Figure 10. The cyclic behavior of a buckled pipe (Loop B) is compared with the response of a similar pipe with no visible local damage (Loop A). The numerical results show that in the case of buckled pipes, the buckle depth is gradually increased with the accumulation of plastic deformation in the critical region. The hysteresis loop in the case of the non-buckled member appears to be stable, so that the plastic deformation remains constant at each cycle. Moreover, as summarized in Table 2, for the nonbuckled pipe, the SNCF factor is computed equal to 1.7 while for the case of the buckled pipe the SNCF factor value becomes equal to 17.5. From this comparison, it is concluded that significant local strains occur at the buckled area and fatigue failure may occur, despite the fact that the buckle deformations fall within the limits of geometrical and strain criteria reported in the current ASME B31.8 provisions [11].

Finally, the critical region of the maximum strain accumulation is identified at the middle of the buckle profile at the inward part ("valley" of the buckle), in the longitudinal direction of the pipe. 


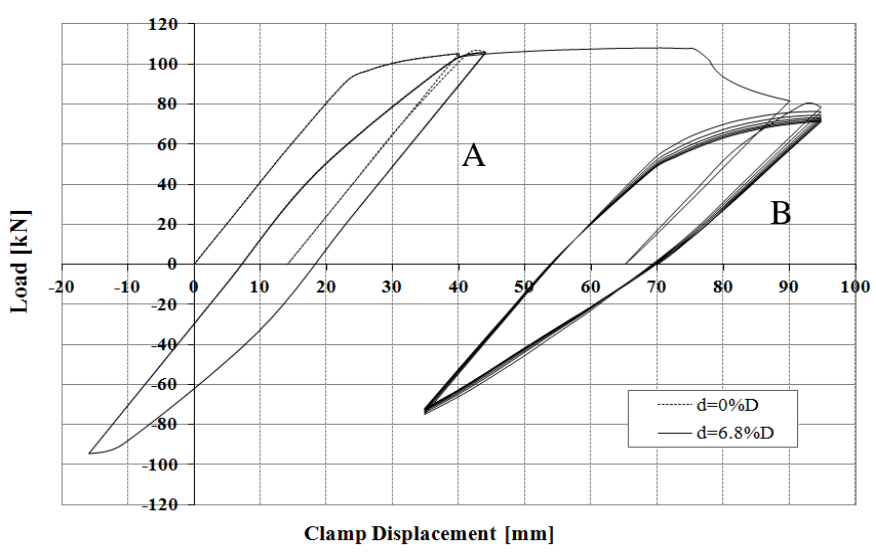

(a)

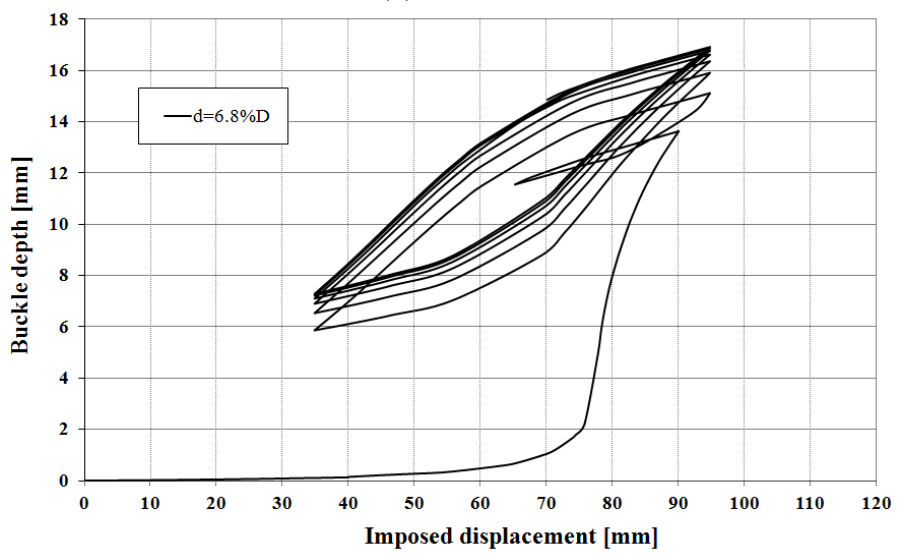

(b)

Figure 10: Cyclic loading behavior for buckled pipes $(\mathrm{d} / \mathrm{D}=6.8 \%)$.

\section{Cyclic pressure loading}

Six (6) cycles of internal pressure fluctuation are applied to the pipes with buckle depth equal to $\mathrm{d} / \mathrm{D}=3.3 \%$ and $6.8 \%$. The maximum value of internal pressure $\left(P_{\max }\right)$ is obtained from Eq. (1) and the ratio of minimum-to-maximum pressure (R) is obtained equal to 0.1 . For internal pressure cyclic loading, the strain concentration factor is computed considering the maximum strain in the hoop direction. Furthermore, the corresponding nominal strain is computed from elementary mechanics of materials as follows:

$$
\Delta \varepsilon_{\text {nom }}=\frac{D}{2 t} \frac{\left(1-v^{2}\right)}{E} \Delta p
$$

where $D$ and $t$ are outer diameter and thickness of the pipe, respectively. $E$ and $v$ are the Young's modulus of the pipe material and the Poisson's ratio, respectively, while $\Delta p$ is the range of the imposed displacement which is constant for every cycle.

The results are also shown in Table 2; increasing the buckle depth, the SNCF factor increases significantly, due to excessive plastic deformation initially developed during the buckle formation.
Table 2. Finite element results for buckled pipes

\begin{tabular}{|c|c|c|c|c|c|c|c|}
\hline \multirow[t]{2}{*}{$\begin{array}{l}\text { BUCKLED } \\
\text { PIPE }\end{array}$} & \multirow{2}{*}{$\begin{array}{l}\text { Depth }\left(\mathbf{d}_{b}\right) \\
{[\mathrm{mm}]}\end{array}$} & \multirow[t]{2}{*}{$\begin{array}{l}d / D \\
(\%)\end{array}$} & \multicolumn{2}{|c|}{$\begin{array}{l}\text { Geometric Strain } \\
\text { Calculations } \\
\text { (ASME B31.8) }\end{array}$} & \multirow[t]{2}{*}{$\begin{array}{c}\text { Cyclic } \\
\text { Bending } \\
\Delta \mathbf{u}[\mathrm{mm}]\end{array}$} & \multirow{2}{*}{$\begin{array}{c}\text { Cyclic } \\
\text { Pressure } \\
\Delta \mathrm{P} \\
{[\mathrm{MPa}]}\end{array}$} & \multirow[t]{2}{*}{ SNCF } \\
\hline & & & $\varepsilon_{\mathrm{i}}(\%)$ & $\varepsilon_{0}(\%)$ & & & \\
\hline 1 & No buckle & -- & -- & -- & 60 & -- & 1.7 \\
\hline 2 & 5.62 & 3.3 & 6.34 & 6.73 & 60 & -- & 18.3 \\
\hline 3 & 6.21 & 3.6 & 6.29 & 6.78 & 60 & -- & 16.85 \\
\hline 4 & 11.54 & 6.8 & 8.9 & 10.8 & 60 & -- & 17.6 \\
\hline 5 & 5.62 & 3.3 & 6.34 & 6.73 & -- & $0.648 \mathrm{P}_{\mathrm{y}}$ & 5.95 \\
\hline 6 & 11.54 & 6.8 & 8.9 & 10.8 & -- & $0.648 \mathrm{P}_{\mathrm{y}}$ & 7.77 \\
\hline
\end{tabular}

\section{CONCLUSIONS}

The present research described the cyclic loading response of locally damaged (dented and buckled) pipes, focusing on the concentration of plastic deformation at the critical dent/buckled region. This deformation, under repeated loading may lead to low-cycle fatigue. Experimental investigation is planned in order to enhance and validate the finite element results presented in this study and propose possible enhancements on the current pipeline assessment methodologies, towards more reliable pipeline integrity.

\section{ACKNOWLEDGEMENT}

This research has been co-financed by the European Union (European Social Fund - ESF) and Greek national funds through the Operational Program "Education and Lifelong Learning" of the National Strategic Reference Framework (NSRF) - Research Funding Program: Heracleitus II. Investing in knowledge society through the European Social Fund.

\section{REFERENCES}

[1] Doglione, R., and Firrao, D., 1998, "Structural Collapse Calculations of Old Pipelines," Int. J. Fatigue, 20 (2), pp. 161-168.

[2] Netto, T. A., Ferraz, U. S., and Estefen, S. F., 2005, "The Effect of Corrosion Defects on the Burst Pressure of Pipelines," J. Constr. Steel Res., 61 (8), pp. 1185-1204.

[3] Cosham, A., and Hopkins, P., 2004, "The Effect of Dents in Pipelines-Guidance in the Pipeline Defect Assessment Manual," Int. J. Pressure Vessels Piping, 81, pp. 127-139.

Ong, L. S. 1991, "Derivation of Stress Associated with a Long Axial Dent in a Pressurized Cylinder," Int. J. Mech. Sci., 33 (2), pp. 115-123.

Ong, L. S., Soh, A. K., and On, J. L., 1992, "Experimental and Finite Element Investigation of a Local Dent on a Pressurized Pipe," J. Strain Analysis, 27 (3), pp. 177-185.

[6] Fowler, J. R., 1993, "Criteria for Dent Acceptability in Offshore Pipelines," Offshore Technology Conference, OTC 7311, Houston, pp. 481-493.

[7] Buitrago, J., and Hsu, T. M., 1996, "Stress Concentration Factors for Dented Tubular Members," Offshore Mechanics \& Artic Engrg Conference, OMAE, Vol. I, pp. 291-296. 
[8] Macdonald, K. A., and Cosham, A., 2005, "Best Practice for the Assessment of Defects in Pipelines-Gouges and Dents," Eng. Failure Anal., 12 (5), pp. 720-745.

[9] Das, S., Cheng, J. J. R., Murray, D. W., 2007, "Prediction of the fracture life of a wrinkled steel pipe subject to low cycle fatigue load.", Canadian Journal of Civil Engineering, 34 (9), pp. 1131-1139.

[10] Dama, E., Karamanos, S. A. and Gresnigt, A. M., 2007, "Failure of Locally Buckled Pipelines.", ASME Journal of Pressure Vessel Technology, 129, pp. 272-279.

[11] ASME B31.8 Gas transmission and distribution piping systems. 2007 ed. ASME, 2007

[12] Yablonskikh Y., "Assessment and analysis of pipeline buckles," GE Oil and Gas PII Pipeline Solutions, Aberdeen, November 2007.

\section{APPENDIX - Dent acceptability in ASME B31.8}

According to Appendix R of the ASME B31.8 code, it is possible to estimate the maximum strain in a dent assuming the total strain is the combination of bending strain in the circumferential direction, the bending strain in the longitudinal direction and the membrane (stretching) strain in the longitudinal direction. Each one of those strain components is evaluated separately; then, assuming that each component occurs coincidently at the dent apex, the components are accordingly combined to determine the total strain.

The following equations are proposed in [11] for the evaluation of the bending strain in the circumferential direction $\left(\varepsilon_{1}\right)$, and the bending and membrane strains in the longitudinal direction $\left(\varepsilon_{2}\right.$ and $\left.\varepsilon_{3}\right)$ :

$$
\begin{aligned}
& \varepsilon_{1}=\frac{t}{2}\left(\frac{1}{R_{0}}-\frac{1}{R_{1}}\right) \\
& \varepsilon_{2}=-\frac{1}{2 R_{2}} \\
& \varepsilon_{3}=\frac{1}{2}\left(\frac{d}{L}\right)^{2}
\end{aligned}
$$

where $R_{0}$ is the radius of curvature of the undeformed pipe surface (equal to half of the nominal pipe outside diameter), and $t, d, L$ correspond to the wall thickness, dent depth and dent length respectively in the longitudinal direction. The external surface radii of curvature $R_{1}$ and $R_{2}$ (see Figure 11) are measured, respectively, in the transverse and longitudinal planes through the dent. The value of $R_{1}$ is positive when the dent partially flattens the pipe, i.e. when the curvature of the pipe surface in the transverse plane is in the same direction as the original surface radius of curvature $R_{0}$. Otherwise, if the dent is re-entrant (corresponding to wall inversion), the value of $R_{1}$ is negative. The curvature $R_{2}$ as used in the code always has a negative value.
Subsequently, the total strain on the inner and outer pipe surfaces (respectively $\varepsilon_{i}$ and $\varepsilon_{o}$ ) are then given by the following expressions:

$$
\begin{aligned}
& \varepsilon_{i}=\sqrt{\varepsilon_{1}^{2}-\varepsilon_{1}\left(\varepsilon_{2}+\varepsilon_{3}\right)+\left(\varepsilon_{2}+\varepsilon_{3}\right)^{2}} \\
& \varepsilon_{o}=\sqrt{\varepsilon_{1}^{2}+\varepsilon_{1}\left(-\varepsilon_{2}+\varepsilon_{3}\right)+\left(-\varepsilon_{2}+\varepsilon_{3}\right)^{2}}
\end{aligned}
$$

The dent is considered as acceptable when the larger of the values of $\varepsilon_{i}$ and $\varepsilon_{o}$ is lower than the allowable strain limit. For smooth dents, which do not include gauges or welds, the allowable strain limit is $6 \%$

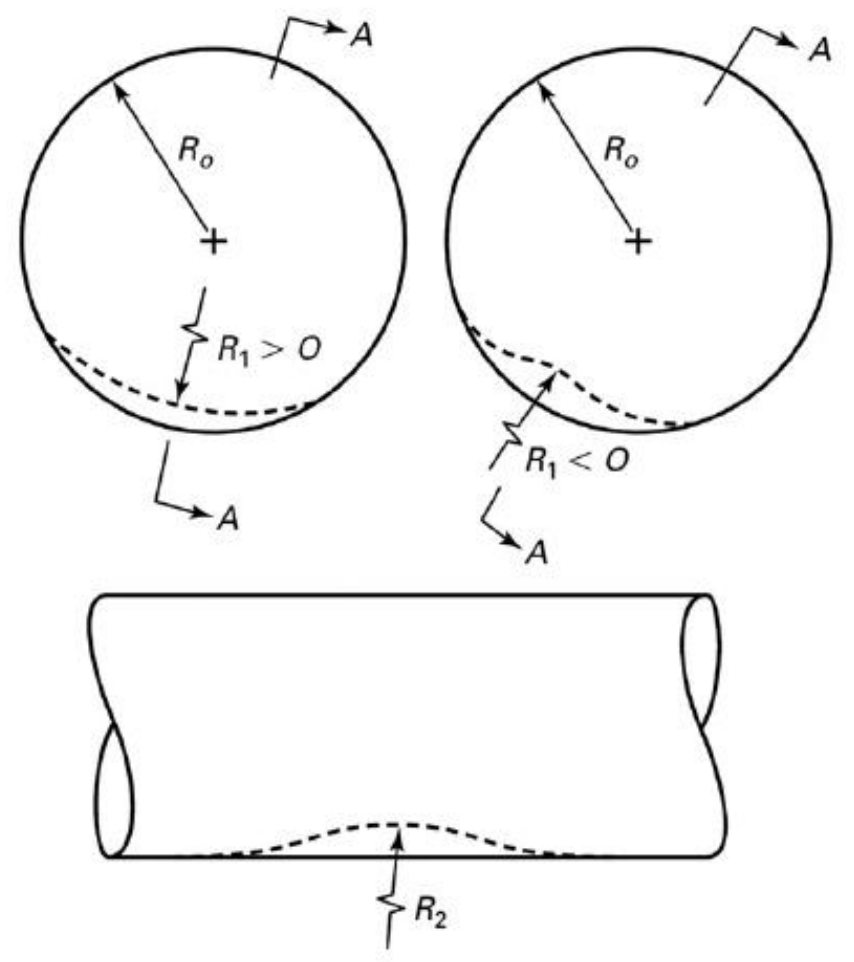

Figure 11: Local curvatures for estimating strain in smooth dents [12]. 


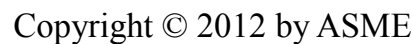

